\title{
O ALEITAMENTO MATERNO COMO FATOR BENÉFICO E PREVENTIVO CONTRA MALOCLUSÕES
}

\section{BREASTFEEDING AS A BENEFICIAL AND PREVENTIVE FACTOR AGAINST MALOCCLUSIONS: A LITERATURE REVIEW}

Pâmella Vieira Lopes Odotontóloga formada pela Universidade de Rio Verde - UniRV, Brasil

E-mail: pamvieiralopes@hotmail.com Orcid: https://orcid.org/0000-0001-6117-4125

Roberta Cristina Costa Guimarães Odotontóloga formada pela Universidade de Rio Verde - UniRV, Brasil

E-mail: robertaccostaguimaraes@gmail.com Orcid: https://orcid.org/0000-0002-6603-1163

Vanessa Viana Azevedo Torres Mestre em Odontopediatria, Universidade de Rio Verde - UniRV, Brasil

E-mail: vanessaviana@unirv.edu.br Orcid: https://orcid.org/0000-0002-7115-3798

Alessandro Rogerio Giovani Doutor em Endodontia, Universidade de Rio Verde - UniRV, Brasil

E-mail: drgiovani@unirv.edu.br Orcid: https://orcid.org/0000-0001-9594-6250

Adriana Vieira Macedo Brugnoli Mestre em Fisioterapia, Universidade de Rio Verde - UniRV, Brasil

E-mail: adriana.brugnoli@unirv.edu.br Orcid: https://orcid.org/0000-0002-7804-0331

Heloísa Silva Guerra Mestre em Saúde Coletiva, Universidade de Rio Verde - UniRV, Brasil

E-mail: heloisaguerra@unirv.edu.br Orcid: https://orcid.org/0000-0002-0617-8112

Renato Canevari Dutra da Silva Mestre em Ciências da Saúde, Universidade de Rio Verde - UniRV, Brasil

E-mail: renatocanevari@unirv.edu.br Orcid: https://orcid.org/0000-0002-6428-2823

Recebido: 16/06/2021 - Aceito: 17/06/2021 


\section{Resumo}

O aleitamento materno é fundamental para o crescimento, desenvolvimento, saúde e nutrição dos bebês, sendo uma ferramenta acessível e correta. Através do ato de amamentar, a criança estimula um exercício físico contínuo que proporciona o desenvolvimento do sistema estomatognático e a prevenção precoce de hábitos deletérios e maloclusões em que podem se desenvolver e influenciar no curso da vida do indivíduo. Trata-se de um estudo que objetivou analisar os benefícios do aleitamento materno para o sistema estomatognático e como fator preventivo contra maloclusões. O presente estudo, de cunho bibliográfico, foi realizado através de pesquisas em plataformas. Frente a esse estudo, conclui-se que o aleitamento possui inúmeros benefícios de curto e longo prazo para as crianças, e possivelmente é um fator que favorece um correto desenvolvimento craniofacial. Sendo assim, a Odontologia atualmente pode atuar preventivamente desde a vida intrauterina, através de recomendações a gestantes para a sua saúde bucal e geral, e de forma positiva para a saúde do lactante.

Palavras-chave: Aleitamento materno. Desenvolvimento craniofacial. Hábitos deletérios.

\section{Abstract}

Breastfeeding is essential for the growth, development, health and nutrition of babies, being an accessible and correct tool. Through the act of breastfeeding, the child encourages continuous physical exercise that promotes the development of the stomatognathic system and the early prevention of harmful habits and malocclusions in which they can develop and influence the individual's life course. This study aimed to analyze the benefits of breastfeeding for the stomatognathic system and as a preventive factor against malocclusions. The present study, of bibliographic nature, was carried out through research in platforms. Based on this study, it is concluded that breastfeeding has numerous short and long-term benefits for children and is possibly a factor that favors correct craniofacial development. Thus, Dentistry can currently act preventively from intrauterine life, through recommendations to pregnant 
women for their oral and general health, and in a positive way for the health of the infant.

Keywords: Breastfeeding. Craniofacial development. Deleterious habits.

\section{INTRODUÇÃO}

O aleitamento materno é o meio utilizado pela mãe para suprir as necessidades fisiológicas do bebê, como nutrição, sucção, deglutição, respiração, crescimento e desenvolvimento do sistema estomatognático e de sua saúde geral. O aleitamento possui inúmeros benefícios de curto e longo prazo para as crianças, e possivelmente é um fator que favorece um correto desenvolvimento craniofacial.

Esse presente estudo é relevante para ressaltar os benefícios do aleitamento materno tanto para a saúde geral quanto para o sistema estomatognático e a correlação de quais formas a via de alimentação pode estimular ou alterar o desenvolvimento desta região e, estender a promoção de saúde associada a informações sobre $\mathrm{o}$ aleitamento materno, principalmente para gestantes e cirurgiões-dentistas.

Contudo o objetivo do presente estudo foi abordar os benefícios do aleitamento materno para o sistema estomatognático e como fator preventivo contra maloclusões.

\section{MÉTODOS}

Para o presente estudo, de cunho bibliográfico, foram realizadas pesquisas em plataformas como SciELO, PubMed, Google Acadêmico e Biblioteca Virtual em Saúde, com informações atualizadas, pesquisas essas também realizadas na Biblioteca Central da Universidade de Rio Verde (UniRV), pertinentes ao tema. Para a busca das publicações utilizaram-se palavras-chave: aleitamento materno, desenvolvimento craniofacial e hábitos deletérios. Foram estabelecidos como critérios para inclusão as publicações que foram publicadas em língua inglesa ou portuguesa, ter sido publicado entre 2000 a 2020. 


\section{REVISÃO DE LITERATURA}

\section{BENEFÍCIOS DO ALEITAMENTO MATERNO NA SAÚDE BUCAL DA CRIANÇA}

A lactação é considerada uma atividade de todas as espécies de mamíferos. Nos humanos, o aleitamento é alimento "padrão ouro" nos primeiros meses de vida (KROL; GROSSMANN, 2018).

O aleitamento materno é essencial para o crescimento, desenvolvimento, saúde e nutrição dos bebês, sendo uma intervenção acessível e adequada. A literatura relata que o aleitamento materno até aos seis meses, reduzindo os riscos de hospitalização e inúmeras doenças infantis, entre crianças no primeiro ano de vida, e trabalha a musculatura peribucal, que está ligado ao desenvolvimento correto dos padrões ósseos e musculares, o desenvolvimento facial harmônico é importante não somente por fatores de estética, mas também devido ao funcionamento do sistema mastigatório, evitando que a criança precise de uma correção ortodôntica, protética e cirúrgica do conjunto dento-maxilo-mandibular e suas estruturas adjacentes, além de causar fadiga nesses músculos, promove juntamente a satisfação da criança ao sugar e não sinta falta de uma sucção não nutritiva, livrando-se do uso de bicos artificiais (MOIMAZ et al., 2017).

Nas últimas três décadas, a prevalência de aleitamento materno no Brasil apresentou-se tendência ascendente, em que os principais ganhos foram vistos entre 1986 e 2006, seguida de relativa estabilização em 2013. Foram vistos que nos países de baixa e média renda, apenas 37\% das crianças menores de seis meses são exclusivamente amamentadas. Níveis exemplares de amamentação conseguiriam prevenir mais de 823.000 mortes de crianças menores de cinco anos por ano no mundo (REZENDE et al., 2019).

Os mecanismos de amamentação em bebês são complexos e necessitam do sistema nervoso central a coordenação dos processos de sucção, respiração e deglutição (LOPES; MOURA; LIMA, 2013). 
O mecanismo da amamentação ocorre, pela apreensão do mamilo, vedando a cavidade bucal e em seguida pela pressão do mamilo para a sucção do leite. Havendo a formação do vácuo que propicia a vedação e à contração do mamilo pela língua, oferecendo a extração do leite do seio para que ser deglutido e trazendo a mandíbula à sua posição original (BATISTA; TRICHES; MOREIRA, 2011).

Funções primárias do bebê como sucção, deglutição e respiração são conseguidas através de uma forma correta de amamentação. Mamar não supre apenas a necessidade de nutrir e se sentir alimentado, mas também a "fome de sucção", que está envolvido com fatores emocionais, psicológicos e orgânicos. Se a criança não é suprida dessa necessidade de sucção, causará insatisfação emocional, fazendo com que a busque em outros meios como dedo, chupeta, ou objetos, levando a hábitos deletérios (ANTUNES et al., 2008).

Através do ato de amamentar, a criança estimula um exercício físico contínuo que proporciona o desenvolvimento da musculatura e ossatura bucal, oferecendo o desenvolvimento facial harmônico. Orienta o crescimento de estruturas, como seio maxilar para respiração e fonação, desenvolvimento do tônus muscular, crescimento ântero-posterior dos ramos mandibulares, anulando o retrognatismo mandibular. Além disso, evita alterações no sistema estomatognático: prognatismo mandibular, musculatura labial superior hipotônica, musculatura labial inferior hipertônica, atresia de palato, interposição de língua, atresia do arco superior e impede mal oclusões como mordida aberta anterior, mordida cruzada posterior e aumento de sobressalência (ANTUNES et al., 2008).

O aleitamento materno oferece uma respiração adequada e ocasiona uma excelente relação entre as estruturas duras e moles do sistema estomatognático, proporcionando uma correta postura de língua e vedamento dos lábios. Também está vinculada ao mecanismo de sucção, que desenvolve os órgãos fonoarticulatórios e a articulação dos sons das palavras, evitando hábitos deletérios e patologias fonoaudiológicas (ANTUNES et al., 2008).

O desenvolvimento da articulação temporomandibular (ATM) também está envolvida com o aleitamento. Se a articulação recebe pouco esforço muscular para extrair alimentação, como na amamentação artificial, pode ocasionar uma anulação da excitação da ATM e da musculatura mastigatória do recém-nascido (ANTUNES et al., 2008). 
A amamentação natural é um fator importante para os portadores de fissuras, pois, o ato de sucção com mais força estimula o desenvolvimento da musculatura da face e amplia a força dos movimentos executados com a língua (BATISTA; TRICHES; MOREIRA, 2011).

A prevenção precoce de qualquer mal oclusão em desenvolvimento pode influenciar no curso de vida de qualquer indivíduo e ajuda a evitar tratamentos ortodônticos longos e caros (PERES et al., 2018).

A American Academy of Pediatric Dentistry (AAPD) revisou a Diretriz sobre Saúde Bucal Infantil em 2012 acrescentou que o leite materno é excepcionalmente superior no fornecimento de melhor nutrição possível para crianças e não foi epidemiologicamente associado à cárie, porém a "amamentação mais de 7 vezes diariamente após os 12 meses está associado a um risco aumentado de cárie na primeira infância (ECC) (ALLISON et al., 2015).

Portanto, a AAPD recomenda iniciar a higienização oral após a erupção do primeiro dente. Várias literaturas correspondem com esta recomendação de higienização oral, visto que suas pesquisas descrevem que o leite materno apresenta alto potencial para causar cárie dentária, e demonstram ser maior cariogênico em relação ao leite de vaca (ALLISON et al., 2015).

Aparenta que o leite materno amplifica a formação de biofilme de $S$. mutans. As amostras de todos os 11 indivíduos apresentaram um aumento no biofilme. Os resultados desta pesquisa validam a recomendação da AAPD para iniciar as medidas de higiene oral dado que o primeiro dente irrompe. Mas, devido a muitos outros fatores e complexas interações, ainda é difícil discernir se o leite materno, de fato, pode causar lesão cariosa na primeira infância diretamente (ALLISON et al., 2015).

Diante da saúde bucal, embora haja indícios, não há evidências científicas suficientes que afirmem que o leite materno possa contribuir para o surgimento da cárie, sendo essa uma questão complexa e equivocada por muitas variáveis (MOIMAZ et al., 2017).

As evidências científicas presentes demonstram que o aleitamento materno é mais eficiente na prevenção da doença cárie na primeira infância do que na alimentação com mamadeira. Apesar de a duração do aleitamento materno nos estudos analisados não puderam ser vistos na revisão sistemática, o aleitamento 
deve ser recomendado como método de alimentação exclusivo por até 6 meses, seguido de amamentação complementar por até dois anos por todas as crianças, conforme a OMS e recomendações do UNICEF (AVILA et al., 2015).

\section{ATIVIDADE MUSCULAR}

A atividade muscular para a extração do leite na amamentação age como agente determinante para o desenvolvimento craniofacial correto, pela exorbitante ginástica da musculatura orofacial, desenvolvendo também a respiração, deglutição, mastigação e fonação (MENINO et al., 2009).

Quando ocorre o desenvolvimento do músculo, em massa e função, ele ultrapassa o osso em que está inserido, tanto em tamanho quanto em capacidade mecânica. Portanto, em busca de equilíbrio, o osso passa por remodelação. Entendendo esse conceito, compreende-se que a origem dos sinais que controla o crescimento de um osso está nos músculos, língua, lábios, bochechas, tegumento, mucosas, tecidos conjuntivos, nervos, vasos sanguíneos, espaço aéreo, faringe, cérebro como massa orgânica, tonsilas, adenoides, e assim por diante. Todos oferecem os sinais de informações que definem o ritmo dos tecidos histogêneos que formam o desenvolvimento de um osso (MENINO et al., 2009).

Os movimentos que estão envolvidos no mecanismo de ordenha são: abaixar, protruir, elevar e retruir a mandíbula. Cerca de 20 músculos contribuem desse mecanismo, os mesmos que serão futuramente usados na mastigação (MENINO et al., 2009).

O músculo masseter mostrou-se ser um músculo que participa de forma ativa na função da sucção, protraindo, elevando e retraindo a mandíbula, assim como os supra-hióideos, os quais contribuem na movimentação e estabilização da mandíbula e na movimentação da língua (RAPOSO; SILVA, 2013).

No presente estudo relata equilíbrio entre as atividades dos músculos masseter e supra-hióideos no decorrer da alimentação por translactaçãoe na amamentação. No uso do copo, ocorre outro mecanismo de atividade destes músculos, sendo o masseter mais ativo do que os supra-hióideos (RAPOSO, 2012).

Visto que no movimento de protrusão, possuem distensão máxima das fibras retrodiscais, que se inclui tanto no menisco quanto no côndilo. Esse movimento não 
é visto na alimentação por mamadeira e algumas pesquisas propõem que este seja o estímulo fundamental para o crescimento mandibular, explicando relatos da literatura que sugerem maior desenvolvimento mandibular em crianças amamentadas. O benefício da amamentação, em comparação com a mamadeira, é que, a criança deve ativar e protruir a musculatura dos maxilares de modo amplo para ordenhar o leite para fora da mama, o que proporciona o crescimento da mandíbula. Esse movimento é essencial, pois a mandíbula, ao nascimento, mostrase menor em tamanho e, em proporção, comparado com a maxila (retrognatismo fisiológico do recém-nascido, que pode chegar a $12 \mathrm{~mm}$ de diferença). Espera-se que até aos seis meses essa desproporção terá de ser corrigida para se ter desenvolvimento facial harmônico (MENINO et al., 2009).

A eletromiografia (EMG) é a técnica que assinala as variações de voltagem geradas pela membrana das fibras musculares em resposta à ativação fisiológica dos músculos esqueléticos. Nas últimas décadas têm sido empregadas como instrumento em pesquisas científicas para a análise da atividade muscular nas funções de sucção e deglutição de bebês e suas possíveis implicações no crescimento das estruturas orais e no desenvolvimento funcional de bebês pré-termo e a termo (RAPOSO, 2012).

\section{RESPIRAÇÃO}

Desde o nascimento a respiração está presente como um reflexo neuromuscular congênito não condicionado importante para a manutenção da vida (NETO et al., 2009).

Dentro do fisiologismo respiratório, a passagem do ar pelas fossas nasais é o mecanismo que oferece a funcionalidade natural do sistema respiratório, enquanto a passagem do ar pela boca altera o caráter oclusivo, havendo um padrão respiratório bucal como um reflexo condicionado indesejável. Quando a alteração da fisiologia respiratória proporciona a respiração bucal uma atividade habitual crônica, alterações patológicas podem desencadear-se durante a vida do indivíduo e, influenciando em diversas áreas da saúde humana (NETO et al., 2009).

A respiração é considerada uma função inata e considerada adequada quando predominantemente nasal. Proporciona crescimento e desenvolvimento 
correto do complexo craniofacial, oferecendo oclusão labial, mandíbula em postura de repouso e língua contida na cavidade oral em contato com o palato, equilibrandose com as forças restritivas do músculo bucinador, sendo coadjuvante do crescimento transversal da maxila (IETO; REHDER; BIANCHINI, 2011).

O estudo "Hipótese da Gênese da Respiração Bucal" propõe bases sobre o surgimento da respiração bucal(NETO et al., 2009).

A instalação da síndrome do respirador bucal não se começa quando há obstrução parcial ou total das vias aéreas superiores pelo desenvolvimento hipertrófico da mucosa nasal, mas ocorre quando há perda do vedamento labial, consequentemente da interação de fatores positivos e negativos sobre o complexo neurológico, ósseo e muscular (NETO et al., 2009).

Considera-se que os hábitos de sucção nutritivos e não nutritivos e as alterações respiratórias ocorridas durante os primeiros meses de vida atuariam como fatores negativos condicionantes ao vedamento labial, entanto a amamentação e a estimulação da respiração nasal da criança atuariam como fatores positivos condicionantes (NETO et al., 2009).

O estudo sobre a gênese da respiração bucal tentou buscar os fatores e os momentos em que os fatores funcionam de maneira mais ampla precipitando a ocorrência da perda do vedamento labial. Portanto, é prematuro afirmar que todos os indivíduos que desenvolvem a perda do vedamento labial desenvolverão, irreversivelmente, a respiração mista ou bucal. Não é determinado porque boa parte dos respiradores bucais mistos não se tornam respiradores bucais restritos, mas é entendível que a respiração bucal surge a partir da perda do vedamento labial (NETO et al., 2009).

A manifestação da respiração bucal está ligada à diminuição do vedamento labial e do aleitamento materno e, também, com o uso da mamadeira e da sucção de chupeta (NETO et al., 2009).

Cerca de cinco meses, o aleitamento materno apresenta-se como um fator de proteção importante para a prevenção da perda do vedamento labial, mantendo-se até em torno dos 16 meses. Porém, é por volta dos 12 meses que o aleitamento materno consegue atingir o seu auge na proteção da perda do vedamento labial (NETO et al., 2009). 
A fisiologia da amamentação explica que, durante esse ato, o mamilo do seio materno sela inteiramente a boca da criança, impedindo a entrada de ar pela boca e forçando a passagem através do espaço aeronasal. Esse ato de amamentação propicia o aumento da força de vedamento labial, prevenindo o reflexo condicionado indesejável da respiração bucal (NETO et al., 2009).

O presente estudo aponta que $90,5 \%$ das crianças que foram amamentadas por menos de seis meses terem sido classificadas como respiradoras bucais (REZENDE et al., 2019).

Crianças que são respiradoras bucais são mais predispostas ao desenvolvimento de alterações faciais, mau posicionamento dentário, postura inadequada e distúrbios da fala. Essa circunstância ainda pode desenvolver e desencadear doenças cardiorrespiratórias, endócrinas, distúrbios de aprendizado, distúrbios do sono e transtornos do humor, que atingem significativa e negativamente a saúde geral e a qualidade de vida (LOPES; MOURA; LIMA, 2013).

Considera-se insustentável a afirmação de que a hipertrofia da adenóide, o desvio de septo nasal, a hipertrofia da mucosa dos cornetos nasais, a atresia maxilar, o palato ogival, a mordida aberta anterior, a mordida cruzada posterior, o perfil facial longo, as modificações no comportamento das curvaturas da coluna vertebral e do músculo diafragma sejam as etiologias da respiração bucal. Sendo assim são consequências da cronicidade da respiração bucal(NETO et al., 2009).

O ronco, ao dormir, é considerado o principal distúrbio respiratório associado a perda do vedamento labial, como resultado do reflexo da respiração bucal (NETO et al., 2009).

A amamentação por mamadeira implica negativamente no desenvolvimento orofacial e conduz à perda de selamento labial e, também favorece uma posição inadequada da língua e alteração da forma da mandíbula (LOPES; MOURA; LIMA, 2013).

hábito oral de sucção não nutritiva (chupeta ou dedo) demonstrou ter efeitos prejudiciais diretos e indiretos sobre a saúde da criança. Quando um bebê faz uso frequentemente de chupeta, ele/ela eventualmente inicia respiração bucal devido a uma postura muscular facial e lingual compensatória hipotônica. No presente estudo, noticiaram que os hábitos de sucção não nutritiva estavam ligados ao padrão de respiração das crianças, e os que possuem esses hábitos 
manifestaram-se mais propensos a desenvolver um padrão de respiração oral (LOPES; MOURA; LIMA, 2013).

Uma maior duração de aleitamento materno amplia a probabilidade de uma criança desenvolver um padrão de respiração normal. Carecem ser realizadas estratégias e programas motivacionais para aumentar a conscientização das mães, de modo a tornar a amamentação mais capaz e segura (LOPES; MOURA; LIMA, 2013).

\section{VIA DE ALIMENTAÇÃO E DESENVOLVIMENTO CRANIOFACIAL}

O aleitamento materno é fundamental durante os seis primeiros meses de vida, diminuindo a hipótese de haver um hábito bucal deletério, sendo que o hábito mais encontrado é o de sucção digital e/ou chupeta (GISFREDE et al., 2016).

No aleitamento através da mamadeira há um fluxo bem maior do que na amamentação natural. A criança se nutre mais rápido, porém com menor esforço. $A$ falta de tais estímulos durante a amamentação, desencadeia um desequilíbrio de forças da musculatura da face, peri e intraoral, causando alterações nos padrões de respiração e deglutição, de modo que o equilíbrio no circuito fisiológico (respiração, deglutição e sucção) não se estabeleça, podendo ser agravado com a presença de hábitos deletérios (FERNANDES et al., 2016).

Se o prazer emocional da criança não é atingido em relação à sucção, ela busca por outros substitutos como dedo, chupetas e objetos para satisfazer-se, e esse hábito de sucção é mais alavancado se a criança recebe somente amamentação artificial (FERNANDES et al., 2016).

Após a dentadura decídua, esperamos que a criança não apresente mais o hábito de sucção e troque pelo hábito de morder e pegar. O prolongamento da fase oral não é fisiológico, e a sua continuidade na dentadura mista pode causar a deformação no crescimento e desenvolvimento ósseo, no posicionamento dentário, no processo respiratório, da fala e, como resultado, provocando maloclusões (FERNANDES et al., 2016).

Através de resultados da literatura, apoia-se que o aleitamento materno exclusivo por no mínimo 6 meses seja um fator importante na prevenção da 
síndrome do respirador bucal, da deglutição atípica, de maloclusões e de hábitos deletérios (FERNANDES et al., 2016).

A prática distendida da amamentação e, evitando o uso da mamadeira e bicos artificiais, promove efeitos satisfatórios, não somente evitando o hábito de sucção não nutritivo, mas também estimulando diretamente os hábitos orais adequado para o desenvolvimento da oclusão dentária (ROMERO et al., 2011).

Quando a sucção ocorre através da mamadeira, o bebê recebe uma pequena quantidade de estimulação motoraoral, fazendo com que haja: flacidez da musculatura perioral e da língua, acarretando uma instabilidade na deglutição, deformidade dos dentes e da face, e causando mordida aberta anterior ou lateral e disfunções respiratórias (GISFREDE et al., 2016).

A sucção digital resulta em diversas alterações na dentição, na musculatura peribucal e na oclusão. A sucção de chupeta também apresenta alterações semelhantes, porém o aspecto mais predominante é da mordida aberta anterior. Embora essas alterações sejam similares, e haja dificuldade da paralisação da sucção de dedo, esse hábito pode resultar em agravamento dos efeitos deletérios. As alterações mencionadas na literatura, como resposta a sucção digital persistente após os 4 anos são: retrognatismo mandibular, prognatismo maxilar, mordida aberta, musculatura labial superior hipotônico, musculatura labial inferior hipertônica, atresia do palato, interposição de língua, atresia do arco superior, respiração bucal, calo ósseo na região do polegar e assimetria anterior (GISFREDE et al., 2016).

Segundo Barreto et al (2008), 16 crianças que receberam aleitamento materno têm maiores hipóteses de não desenvolveram hábitos nocivos, pois, houve uma atividade muscular intensificada, fazendo com que os músculos peribucais fadiga, resultando no cansaço da criança, e fazendo com que a mesma não procure outras opções de sucção, como, por exemplo, uso de chupetas dentre outros objetos (apud GISFREDE et al., 2016).

Os hábitos de sucção não nutritiva podem desenvolver mordida cruzada e mordida aberta anterior que são complicadas, é importante informar aos pais sobre os malefícios desse hábito na oclusão e assim prevenindo em tempo hábil o desenvolvimento de maloclusões (MONTALDO et al., 2011). 
O PAPEL DO CIRURGIÃO-DENTISTA NA PROMOÇÃO DE SAÚDE SOBRE O ALEITAMENTO MATERNO PARA GESTANTES

O aleitamento materno é o meio de alimentação mais antigo e eficiente para a espécie humana. O uso desse alimento na saúde da criança é de fundamental importância, sendo indicado como o modo mais efetivo para o desenvolvimento saudável dos lactentes e o único alimento capaz de atender todas as necessidades fisiológicas das crianças menores de seis meses (LIMA; CAZOLA; PÍCOLI, 2017).

A Organização Mundial da Saúde recomenda que o aleitamento materno exclusivo seja fundamental nos primeiros seis meses e complementar até o final do segundo ano de vida da criança (MOIMAZ et al., 2013).

Depois dos seis meses, começar o consumo de alimentos complementares é recomendável para que todas as necessidades nutricionais de uma criança em crescimento sejam completamente atendidas. Porém, manter o aleitamento também é fundamental porque o aporte de $500 \mathrm{ml}$ diários de leite materno ainda será capaz de fornecer cerca de $75 \%$ das necessidades de energia, $50 \%$ das de proteína e $95 \%$ das de vitamina $A$, além da proteção imunológica (TOMA; REA, 2008).

A promoção do aleitamento materno deve ser olhada como ação primordial para a melhoria da saúde e da qualidade de vida das crianças e de sua família. Promover o aleitamento materno é um excelente exemplo de política pública que envolve a família, comunidade, governos e sociedade civil, com custo benefício e impacto sobre o desenvolvimento e saúde infantil (MOIMAZ et al., 2017).

Não é ampla a literatura sobre os benefícios do aleitamento materno para a saúde da mulher. Até o momento, há um envolvimento positivo entre amamentar e apresentar menos patologias como o câncer de mama, certos cânceres ovarianos e certas fraturas ósseas, especialmente coxofemoral, por osteoporose. Averiguar também sobre o efeito do aleitamento no menor risco de morte por artrite reumatoide. Muitas literaturas foram publicadas mostrando como a amamentação se correlaciona com à amenorreia pós-parto e ao consequente maior espaçamento intergestacional. Outros pontos de benefícios para a mulher que amamenta são o retorno ao peso pré-gestacional mais rápido e o menor sangramento uterino pósparto (consequentemente, menos anemia), devido à involução uterina mais rápida provocada pela maior liberação de ocitocina (REA, 2004). 
O envolvimento paterno na amamentação, nos primeiros 10 dias após o parto, é de suma importância para haver continuidade do aleitamento materno, pelas dificuldades que habitualmente podem ocorrer na amamentação. É importante que se forme um elo entre a mãe, pai e o bebê desde a gestação. $O$ apoio do pai na fase de preparação para a maternidade encoraja a mãe a amamentar por mais tempo, e a aprovação do pai para a amamentação é um fator primordial para o sucesso do aleitamento materno (LIMA; CAZOLA; PÍCOLI, 2017).

A Odontologia está atualmente relacionada a atuar preventivamente desde a vida intrauterina, por recomendações a gestantes para a sua saúde bucal e geral, e sendo assim agir de forma preventiva e positiva para a saúde bucal de seus filhos. $A$ orientação sobre o aleitamento materno é fundamental para o desenvolvimento do bebê e é de suma importância para a saúde oral, principalmente pelas consequências que pode haver como hábitos de sucção não nutritivos nos dentes e na face. Portanto, deve os profissionais da saúde, e o cirurgião dentista, motive essa prática e ressalte os benefícios, promovendo saúde bucal do futuro bebê antes mesmo de seu nascimento e ressaltando o papel da prevenção que a amamentação natural tem na aquisição de hábitos de sucção não nutritivos. Sendo assim, a motivação ao aleitamento materno é de importância não somente para evitar desvios na oclusão, mas também para promoção da saúde (MOIMAZ et al., 2013).

\section{CONSIDERAÇÕES FINAIS}

Tendo em vista os benefícios do aleitamento materno para o desenvolvimento craniofacial, é fundamental ressaltar a importância da promoção de saúde para as gestantes. Elas devem estar conscientes dos inúmeros benefícios e as consequências da ausência do aleitamento. A amamentação é um período que está relacionado com o desenvolvimento da oclusão e atua suprindo fatores emocionais, psicológicos e orgânicos. O mecanismo do aleitamento materno evita possíveis maloclusões. A prevenção precoce de qualquer maloclusão em desenvolvimento previne futuros tratamentos complicados. Atualmente, os órgãos públicos ressaltam as benevolências do aleitamento materno para as gestantes e a promoção de saúde crescendo de forma ascendente mesmo havendo habitualmente complicações. 


\section{REFERÊNCIAS}

ALLISON, L. M. et. al. Effect of Human Milk and its Components on Streptococcus Mutans Biofilm Formation. The Journal of Clinical Pediatric Dentistry, v. 39, n. 3, p. 255-61, 2015.

ANTUNES, L. S. et al. Amamentação natural como fonte de prevenção em saúde. Ciência \& Saúde Coletiva, v. 13, n. 1, p. 103-109, 2008.

AVILA, W. M. et al. Breast and Bottle Feeding as Risk Factors for Dental Caries: A Systematic Review and Meta-Analysis. Plos one,Canada, n. 11,e0142922,2015.doi: $10.1371 /$ journal.pone.0142922

BATISTA, L. R. V.; TRICHES, T. C.; MOREIRA, E. A. M. Desenvolvimento bucal e aleitamento materno em crianças com fissura labiopalatal. Revista Paulista de Pediatria, v. 29, n. 4, p. 674-9, 2011.

FERNANDES, A. T. S. et al. Relação entre aleitamento materno e máoclusão.OrtodontiaSPO, v. 49, n. 2, p. 157-62, 2016.

GISFREDE, T. F. et al. Hábitos bucais deletérios e suas consequências em Odontopediatria. Revista brasileira de Odontologia, v. 73, n. 2, p. 144-9, 2016.

IETO, V.; REHDER, M. I. C.; BIANCHINI, E. M. G. Possíveis associações entre o padrão respiratório predominante e o histórico alimentar infantil. RevistaDistúrbios da Comunicação, v. 23, n. 3, p. 285-295, 2011.

KROL, K. M.; GROSSMANN, T. Psychological effects of breastfeeding on children and mothers. BundesgesundheitsblattGesundheitsforschungGesundheitsschutz, v. 61, n. 8, p. 977-985, 2018.

LIMA, J. P.; CAZOLA, L. H. O.; PÍCOLI, R. P. A participação do pai no processo de amamentação. RevistaCogitareEnfermagem, v. 22, n. 1, p. 01-07, 2017.

LOPES, T. S. P.; MOURA, L. F. A. D.; LIMA, M. C. M. P. Association between breastfeeding and breathing pattern in children: a sectional study. Jornal de Pediatria, v. 90, n. 4, p. 396-402, 2014.

MENINO, A. P. et al. Atividade muscular em diferentes métodos de alimentação do recém-nascido e sua influência no desenvolvimento da face. Revista Médica de Minas Gerais, v. 19, n. (4, supl 5), p. 11-18, 2009. 
MOIMAZ, S. A. S. et al. A influência da prática do aleitamento materno na aquisição de hábitos de sucção não nutritivos e prevenção de oclusopatias. Revista de Odontologia da UNESP, v. 42, n. 1, p. 31-36, 2013.

MOIMAZ, S. A. S. et al. Expectativa e prática materna do aleitamento exclusivo e a saúde bucal do bebê. Revista Ciência Plural, v. 3, n. 2, p. 30-41, 2017

MONTALDO, L. et al. Effects of feeding on non-nutritive sucking habits and implications on occlusion in mixed dentition. International Journal of Paediatric Dentistry, v. 21, n. 1, p. 68-73, 2011.

NETO, E. T. S. et al. Fatores associados ao surgimento da respiração bucal nos primeiros meses do desenvolvimento infantil. Revista Brasileira de Crescimento e Desenvolvimento, v. 19, n. 2, p. 237-248, 2009.

PERES, K. G. et al. Breastfeeding and Oral Health: Evidence and Methodological Challenges. Journalof Dental Research, v. 97, n. 3, p. 251-258, 2018.

RAPOSO, R. D. Atividade dos músculos masseter e supra-hioideos em recémnascidos pré-termo durante o uso do copinho, da translactação e na amamentação. 2012. 150 f. Tese (Doutorado em Saúde da Criança e do Adolescente) Universidade Federal de Pernambuco, Recife, 2012. Disponível em:<https://repositorio.ufpe.br/handle/123456789/12983>. Acesso em: 20 junho. 2021.

RAPOSO, R. D.; SILVA, H. Proposta de um protocolo de avaliação da atividade elétrica dos músculos masseter e supra-hióideos em recém-nascidos pré-termo durante a alimentação. Revista CEFAC, v.15, n.4, p. 803-814, 2013.

REA, M. F. Os benefícios da amamentação para a saúde da mulher. Jornal de Pediatria, v. 80, n.5, p. 142-146, 2004.

REZENDE, B. A. et. al. Tempo de amamentação e sinais de respiração oral em crianças com mau desempenho escolar. Revista Distúrbios da Comunicação, v. 31, n. 1, p. 69-76, 2019.

ROMERO, C. C. et al. Breastfeeding and non-nutritive sucking patterns related to the prevalence of anterior open bite in primary dentition. JournalofApplied Oral Science, v. 19 , n. 2, p. 161-8, 2011.

TOMA, T. S.; REA, M. F. Benefícios da amamentação para a saúde da mulher e da criança: um ensaio sobre as evidências. Cadernos de Saúde Pública, v. 24, n. 2, p. 235-246, 2008. 